\title{
Ectonucleotidases in Tumor Cells and Tumor-Associated Immune Cells: An Overview
}

\author{
Letícia Scussel Bergamin,, ${ }^{1}$ Elizandra Braganhol, ${ }^{2}$ Rafael Fernandes Zanin, ${ }^{3}$ \\ Maria Isabel Albano Edelweiss, ${ }^{4}$ and Ana Maria Oliveira Battastini ${ }^{1}$ \\ ${ }^{1}$ Departamento de Bioquímica, Instituto de Ciências Básicas da Saúde, UFRGS, Rua Ramiro Barcelos, 2600-Anexo, \\ 90035-003 Porto Alegre, RS, Brazil \\ ${ }^{2}$ Centro de Ciências Químicas, Farmacêuticas e de Alimentos, UFPel, 96010-610 Pelotas, RS, Brazil \\ ${ }^{3}$ Instituto de Pesquisas Biomédicas and Faculdade de Biociências, PUCRS, 90619-900 Porto Alegre, RS, Brazil \\ ${ }^{4}$ Departamento de Patologia, Hospital de Clínicas de Porto Alegre, UFRGS, 90035-000 Porto Alegre, RS, Brazil
}

Correspondence should be addressed to Ana Maria Oliveira Battastini, abattastini@gmail.com

Received 17 May 2012; Accepted 4 July 2012

Academic Editor: John Stagg

Copyright (C) 2012 Letícia Scussel Bergamin et al. This is an open access article distributed under the Creative Commons Attribution License, which permits unrestricted use, distribution, and reproduction in any medium, provided the original work is properly cited.

\begin{abstract}
Increasing evidence points out that genetic alteration does not guarantee the development of a tumor and indicates that complex interactions of tumor cells with the microenvironment are fundamental to tumorigenesis. Among the pathological alterations that give tumor cells invasive potential, disruption of inflammatory response and the purinergic signaling are emerging as an important component of cancer progression. Nucleotide/nucleoside receptor-mediated cell communication is orchestrated by ectonucleotidases, which efficiently hydrolyze ATP, ADP, and AMP to adenosine. ATP can act as danger signaling whereas adenosine, acts as a negative feedback mechanism to limit inflammation. Many tumors exhibit alterations in ATP-metabolizing enzymes, which may contribute to the pathological events observed in solid cancer. In this paper, the main changes occurring in the expression and activity of ectonucleotidases in tumor cells as well as in tumor-associated immune cells are discussed. Furthermore, we focus on the understanding of the purinergic signaling primarily as exemplified by research done by the group on gliomas.
\end{abstract}

\section{Introduction}

Nucleotide/nucleoside receptor-mediated cell communication is controlled by the action of ectonucleotidases, including the members of the ectonucleoside triphosphate diphosphohydrolases (E-NTPDases, ecto-ATPases, ectoapyrases, EC 3.6.1.5), ectonucleotide pyrophosphatase phosphodiesterases (E-NPP, EC 3.1.4.1), ectoalkaline phosphatases (ALP, EC 3.1.3.1), and ecto-5' -nucleotidase/CD73 (ecto-5' NT/CD73, EC 3.1.3.5), which efficiently hydrolyze ATP, ADP and AMP to adenosine (Ado) [1-3].

The E-NTPDase members differ regarding the preferences for nucleotides as substrates. While NTPDase1/CD39 hydrolyses nucleoside tri- and diphosphates almost equally well, NTPDase2/CD39L1 presents a high preference for nucleoside triphosphates and NTPDase3/CD39L3 and 8 reveal an intermediate preference for ATP over ADP $[1,4-9]$.
In consequence, the action of NTPDase1/CD39 produces almost directly AMP with minor amounts of free ADP in the extracellular space. This functional property implicates the participation of this enzyme in the control of specific $\mathrm{P} 2 \mathrm{Y}$ receptors for nucleoside triphosphates. Otherwise, ADP is transiently produced by the action of NTPDase2/CD39L1, which implicates the generation of agonist for nucleoside diphosphate-sensitive receptors such as platelet P2Y1 and $\mathrm{P} 2 \mathrm{Y} 12$ receptors [2]. The second family of ectonucleotidases is the ectonucleotide pyrophosphatase/phosphodiesterases (E-NPP). The E-NPP family is constituted by seven ectoenzymes, but only the NPP1-3 are involved in the purinergic signaling [2, 10-12]. The final step of nucleotide hydrolysis to generate adenosine is catalyzed by ecto- $5^{\prime}$ nucleotidase/CD73 (ecto-5'-NT/CD73) [1, 13]. In addition, to constitute the major source of extracellular adenosine, other nonenzymatic functions are assigned for this protein. 
Ecto- $5^{\prime}-\mathrm{NT} / \mathrm{CD} 73$ itself acts as a proliferative factor and is involved in the control of cell growth, cell-cell and cellmatrix interactions [14-16].

In this paper, the alterations in the ATP-metabolizing enzymes, especially the ectonucleotidases that may contribute to the physiopathological events observed in solid cancer are discussed.

\section{Ectonucleotidases in Immune Cells}

Extracellular nucleotides and nucleosides play an important role in inflammatory and immune responses. To date, ATP is mainly associated to proinflammatory response whereas adenosine has opposite effects limiting the inflammation by suppressing the actions of immune cells [17-20]. Moreover, the plasticity of immune cells during early phase to resolution of inflammation turns important of the control of these immunomodulatory molecules. Increasing evidence suggests the participation of ectonucleotidases in inflammatory process involving immune cells [21-26]. The ectonucleotidases are expressed in B lymphocytes, natural killers cells (NKs), monocytes, macrophages, dendritic cells (DCs) and subsets of T cells [21-26]. Although the presence of the enzymatic chain responsible for ATP hydrolysis and adenosine production was demonstrated in almost all immune cells, only recently the participation of ectonucleotidases in the control of inflammation has been shown.

The first studies to begin to elucidate the physiological role of E-NTPDases (Ecto-ATPases) in immune cells have been proposed in the early nineties [27-29]. Dombrowski et al. [27] showed evidence that Ecto-ATPase activity was required for activation of effector T cells $\left(\mathrm{CD} 8^{+}\right)$and for antigen recognition [27]. Likewise, upregulation of E-NTPDase activity on $\mathrm{CD} 4^{+}$cells has been described soon after stimulation whereas $\mathrm{CD}^{+}$naïve cells present a negligible activity [30]. In the same study it was shown that the inhibition of E-NTPDase or ATP depletion on $\mathrm{CD}^{+}{ }^{+}$diminished INF- $\gamma$ and IL-2 secretion [30]. Recently the role of adenosine generated by ecto- $5^{\prime}$-nucleotidase/CD73 in graft-versus-host disease was demonstrated. The ecto- $5^{\prime}$-nucleotidase/CD73 deficiency led to enhanced T-cell expansion, IFN- $\gamma$ and IL6 production, and the migratory capacity of $\mathrm{CD} 73^{-/-} \mathrm{T}$ cells [31].

Recent studies have shown the central role of ectonucleotidases in Foxp3+ T regulatory cells (Tregs). The NTPDase1/CD39 and the ecto- $5^{\prime}-\mathrm{NT} / \mathrm{CD} 73$ expressed in Tregs compose one of the immunosuppressive mechanisms associated to these immune cells [32-35]. In addition, alterations in NTPDase1/CD39 and ecto-5'-NT/CD73 machinery may produce more adenosine, which lead to severe immunodeficiency with recurrent infection $[36,37]$. In accordance, recently Tang et al. [38] verified that the NTPDase1/CD39 on Foxp3+ T regulatory cells correlates with progression of hepatitis $\mathrm{B}$ virus infection and it can be associated with other viral infections, and autoimmune diseases [38]. Moreover, it has been reported that lupus patients express low levels of NTPDase1/CD39, and this is associated with reduced generation of adenosine [39].
In relation to the ectonucleotidases in macrophages, some advances have been done. Hyman et al. [40] have reported the importance of NTPDase1/CD39 in the trafficking of monocyte/macrophage during an ischemic process. They showed that inhibition or genetic deletion of NTPDase1/CD39 $\left(\right.$ CD $\left.39^{-/-}\right)$generated an increase in the ischemic area and the leukocytes number (mainly monocytes/macrophages). The data demonstrated that NTPDase1/CD39 reduces stimulation of the P2X7 receptor by modulating $\alpha \mathrm{M} \beta 2$ integrin expression on the surface of monocytes/macrophages, thus controlling their migration [40]. Pelegrin and Surprenant [41] have reported the participation of pyrophosphate originated from extracellular ATP hydrolysis to inhibit IL- $1 \beta$ release in alternative/M2 polarized macrophages. In addition, NTPDase1/CD39, the dominant ectonucleotidase on macrophages, controls the IL- $1 \beta$ secretion by these cells by regulating the $\mathrm{P} 2 \mathrm{X} 7$ receptor activation [26]. Notably, we have shown that NTPDase1/CD39 and ecto- $5^{\prime}-\mathrm{NT} / \mathrm{CD} 73$ are differentially expressed during macrophage polarization, which results in extracellular ATP accumulation in proinflammatory/M1 phenotype while anti-inflammatory or alternative/M2 phenotype generates immunosuppressive adenosine [24].

Although the NTPDase1/CD39 expression has been reported in dendritic cells, little is known about the role of $\mathrm{E}$ NTPDases and other ectonucleotidases in immune function of these cells and its subtypes [42]. For instance, skinresident dendritic cells (Langerhans cells) in $\mathrm{CD}_{39^{-/-}}$mice reveal a dichotomy role in irritant versus allergic contact dermatitis [43]. In the irritant dermatitis there was an exacerbated skin inflammation in $\mathrm{CD} 39^{-/-}$mice indicating that the NTPDase1/CD39 serves as the first line of defense at the environmental interface against nucleotide-mediated inflammatory signals. On the other hand in the allergic contact dermatitis was severely attenuated in these mice by impairing the Langerhans cell with $\mathrm{T}$ cell communication in antigen presentation [43].

Corriden et al. [44] showed the participation of NTPDase1/CD39 chemotaxis regulation by facilitating extracellular ATP hydrolysis in human and neutrophil lineage. Corroborating this data, it has been demonstrated that NTPDase1/CD39 controls IL-8 production in human neutrophils via regulation of $\mathrm{P} 2$ activation [25]. Even though NTPDase1/CD39 is expressed in NK and NK-T cells, the application of this has not yet been fully elucidated.

Of note, NTPDase1/CD39 and ecto-5' ${ }^{\prime}$ NT/CD73 expression by tumor-infiltrated immune cells can lead to adenosine generation, inducing an immune suppression around the tumors. So, these ectoenzymes might allow immune cells to adjust the outcome of the extracellular purinergic cascade in order to fine-tune their functions during the inflammatory set. Therefore, the continuing development of therapeutic strategies targeting the combat for the disordered inflammation and aberrant immune reactivity that involve ectonucleotidases could offer promising finding.

\section{Ectonucleotidases in Solid Cancer}

Cancer development is a multifactorial process consisting of numerous genetic alterations that controls cell proliferation 
and differentiation, including the regulation in oncogenes expression (MDM2, CDK4, EGFR) and tumor suppressor genes (p53, p16, p15, and RB1) [45-48]. However, increasing evidence points that the genetic alteration does not guarantee the development of a tumor and indicates that complex interactions of tumor cells with the microenvironment are fundamental to tumorigenesis. In the tumor microenvironment, the presence of secretory products released by tumor and tumor-associated cells creates a growth factor-rich environment linked to tumor maintenance and growth [49]. A number of studies have investigated the identity of these endogenous signals, their receptors, and signaling pathways using tumor models. The most likely candidates are dying cells or extracellular matrix components, glutamate, nucleotides, and nucleosides, for example, ATP and adenosine, all of which were found to be present in the tumor environment [50-52].

Purinergic signaling involving ATP and the respective breakdown or hydrolytic products such as ADP and adenosine activate their own responses via purinergic receptor activation and modulate cross-talk with chemokines [17]. ATP has been identified as a mitogen for v-myc immortalized neural progenitor cells [53]. In astrocytes, extracellular ATP regulates ERK function by activating $\mathrm{P}_{2} \mathrm{Y}_{1}, \mathrm{P}_{2} \mathrm{Y}_{2}$, or $\mathrm{P}_{2} \mathrm{Y}_{4}$ purinoceptors $[54,55]$ indicating the potential for cross-talk with FGF-, EGF- and PDGF- driven cell mitogenic pathways. Adenosine may accumulate in the tumor interstitium [52] where it modulates cell proliferation and angiogenesis, and suppresses anticancer immune responses [56, 57]. Purines can be released from damaged cells during tumor growing, acting as a classical danger signal for the immune system and as a proliferative stimulus to different cancer kinds. However, purines are also released from host normal cells, immune as well as cancer cells through several active mechanisms, including shear stress, hypotonic swelling, hypoxia, stretching, hydrostatic pressure, as well as in response to $\mathrm{Ca}^{2+}$ mobilizing pharmacological agonists [58-60]. As presented before, nucleotide/nucleoside receptor-mediated cell communication is orchestrated by ectonucleotidases, which efficiently hydrolyze ATP, ADP, and AMP to adenosine [61]. The presence/absence of ectonucleotidases in a variety of human tumors has been reported such as ovarian cancer [62], Walker 256 tumor [63], melanomas [64], colorectal cancer [65], glioma [66], and bladder cancer [67]. Therefore, it is tempting to propose that disruption of ectonucleotidase activity from both tumor and infiltrated cells may constitute important regulators of tumor spread and metastasis. Accordingly, it has shown that ATP accumulates in the tumor interstitium at hundreds micromolar range, while being almost undetectable in healthy tissues [51]. Extracellular ATP may be crucial for the tumor not only as a stimulus for growth but also as a source of an immunosuppressive agent such as adenosine [51].

The anti- or protumor effect target by ectonucleotidases, mainly NTPDase1/CD39, is related to tumor kind and its interaction with stromal, immune and endothelial cells. For example, a study published by Häusler et al. [62] showed aberrant NTPDase1/CD39 and ecto-5'-NT/CD73 expression in human ovarian cancer biopsies. Functional assays in ovarian cancer cell culture applying siRNA against NTPDase1/CD39 and ecto-5' - NT/CD73 or pharmacological inhibitors of $\mathrm{A}_{2 \mathrm{~A}}$ adenosine receptors revealed that tumorderived adenosine inhibits the proliferation of allogeneic human $\mathrm{CD}^{+} \mathrm{T}$ cells as well as cytotoxic effect of $\mathrm{T}$ cell priming and NK cells cytotoxicity [62]. The presence of E-NTPDase and ecto- ${ }^{\prime}$-NT/CD73 has been characterized in Walker 256 tumor, where the NTPDase1/CD39, NTPDase2/CD39L1, and ecto-5'-NT/CD73 were identified as the dominant enzymes expressed, which by regulating the ratio of nucleotides/nucleosides may target tumor growth [63]. On the other hand, in melanomas, an association was observed between NTPDase1/CD39 overexpression, the differentiation degree of tumor cells, and the tumor escape from immunological effectors mechanisms at early stages of tumor progression, indicating a role of purinergic signaling in cell differentiation and antitumor immune response [64]. Indeed, the deletion of NTPDase1/CD39 resulted in reduction of melanoma growth and inhibition of pulmonary metastases, associated with abrogation of angiogenesis [68]. In addition to ectonucleotidases expressed by tumor cells, the nucleotide-metabolizing enzymes present at surface of tumor-associated cells also contribute to tumor growing or inhibition. The NTPDase1/CD39 expression on Treg inhibits NK cell-mediated antitumor activity and is permissive for hepatic metastatic tumor growth, whereas vascular NTPDase1/CD39 boosts angiogenesis [69]. Extracellular ATP limits melanoma cell growth, and this antitumor effect could be overcome by intrinsic NTPDase1/CD39 expression by endothelial cells [70]. The authors suggest targeting the NTPDase1/CD39 activity or expression in combination with conventional therapy could provide a novel approach to cancer treatment [70]. In human follicular lymphoma, it has been observed that, in addition to Treg-suppressing effect, infiltrating $\mathrm{T}$ cells are suppressed by extracellular adenosine, which is produced by ATP-nucleotidase-adenosine system present in lymph node mononuclear cells [71]. Indeed, the selective NTPDase1/CD39 inhibitor and the $A_{2 A}$ and $\mathrm{A}_{2 \mathrm{~B}}$ antagonists partially overcome $\mathrm{T}$ cell suppression [71]. Finally, the increased expression of NTPDase1/CD39 and ecto- $5^{\prime}-\mathrm{NT} / \mathrm{CD} 73$ in Treg cells of patients with head and neck cancer is related to the conversion of ATP to immunosuppressive adenosine. Elevations in adenosine levels are responsible for suppressor functions of $\mathrm{CD} 4^{+} \mathrm{CD} 39^{+}$Treg in patients with an active disease as well as those with no evident disease after successful therapy [32].

Ecto-5'-NT/CD73, originally defined as a lymphocyte differentiation antigen, is thought to function as a cosignaling molecule on $\mathrm{T}$ lymphocytes and is widely expressed on many tumor cell lines and in cancerous tissues $[56,72,73]$, including bladder cancer [67], glioma cell lines [74], melanoma [75], ovarian cancer [76], thyroid cancer [77], esophageal cancer [78], prostate cancer [79], breast cancer [80, 81], and lymphoma [82]. Ecto-5'-NT/CD73 upregulation is associated with a highly invasive cancer phenotype, drug resistance, and tumor-promoting functions [56]. In addition, to produce immunosuppressive adenosine from AMP hydrolysis, ecto- $5^{\prime}-\mathrm{NT} / \mathrm{CD} 73$ acts as an adhesive molecule and interacts with extracellular matrix glycoprotein, such as 
fibronectin and laminin, to produce cancer-invasive properties [56]. Studies suggest that ecto-5'-NT/CD73 expression can enhance breast-cancer cell migration and invasion [81], and its expression has been proposed as prognostic marker to patients. Indeed, the therapy with anti-CD73 monoclonal antibody delayed the breast primary tumor growth and inhibited the development on spontaneous lung metastases [83]. These antitumor effects were dependent on an induction of an adaptive antitumor immune response. In addition, ecto- $5^{\prime}-\mathrm{NT} / \mathrm{CD} 73$ was involved in tumor chemotaxis, and the $A_{2 B}$ adenosine receptor participates in this process [83]. In line with the role of ecto- $5^{\prime}-\mathrm{NT} / \mathrm{CD} 73$ in cancer progression, Zhi et al. [84] evaluated the participation of ecto$5^{\prime}$-NT/CD73 in breast cancer growth by examining the effect of ecto- $5^{\prime}-\mathrm{NT} / \mathrm{CD} 73$ suppression via RNA interference and ecto- $5^{\prime}-\mathrm{NT} / \mathrm{CD} 73$ overexpression on tumor growth in vitro and in vivo. As expected, the cell growth rate was significantly lower after ecto- $5^{\prime}-\mathrm{NT} / \mathrm{CD} 73$ suppression. In opposite, the ecto- $5^{\prime}$-NT/CD73 overexpression increased cell viability and promoted cell cycle progression, depending on its enzyme activity [84]. Taken together, these studies suggest that ecto- $5^{\prime}-\mathrm{NT} / \mathrm{CD} 73$ play an important role in cancer growth by affecting cell cycle progression and apoptosis and by triggering adaptive antitumor immunity and inhibiting metastasis $[83,84]$.

Although the functions of ecto- $5^{\prime}-\mathrm{NT} / \mathrm{CD} 73$ in cancer cells have been investigated to some extent, the contribution of host ecto- $5^{\prime}-\mathrm{NT} / \mathrm{CD} 73$ activity to cancer progression has been recently addressed. In these studies, authors employed ecto- $5^{\prime}$-NT/CD73 gene-targeted mice to investigate the role of host-derived ecto- $5^{\prime}$-NT/CD73 in antitumor immunity, tumor cell metastasis, and carcinogenesis [85-87]. Ecto-5' NT/CD73 deficient mice had significantly elevated ATPase and ADPase activities in T lymphocytes. In a melanoma model, the growth of primary tumors and formation of metastasis were significantly attenuated in mice lacking ecto- $5^{\prime}$-NT/CD73. The intratumoral accumulation of Tregs and mannose receptor macrophages, which are related to tumor malignancy, was also attenuated in ecto- $5^{\prime}$-NT/CD73deficient mice [85]. In addition, it has been shown that the host-derived ecto-5'-NT/CD73 ablation significantly suppressed the growth of colon cancer, lymphoma, mammary tumors, and melanoma [86]. The protective effect of ecto$5^{\prime}$-NT/CD73 deficiency on primary tumors was dependent on $\mathrm{CD}^{+} \mathrm{T}$ cells and associated with an increased frequency of antigen-specific $\mathrm{CD}^{+} \mathrm{T}$ cells in peripheral blood and tumors [86]. Finally, recent studies suggest that host-derived ecto- $5^{\prime}-\mathrm{NT} / \mathrm{CD} 73$ exerts a critical oncogenic function during tumorigenesis. Ecto- $5^{\prime}-\mathrm{NT} / \mathrm{CD} 73$ deficiency suppressed the development of 3-methylcholanthrene- (MCA-) induced fibrosarcomas and also suppressed prostate tumorigenesis in TRAMP transgenic mice. Notably, the treatment with an anti-CD73 monoclonal antibody effectively suppressed growth of established tumors and inhibited the development of TRAMP-C1 lung metastases [87]. Taken together, these data indicate that suppression of ecto- $5^{\prime}-\mathrm{NT} / \mathrm{CD} 73$ activity at multiple levels, including tumor cells, Tregs and nonhematopoietic cells, may be a new tool to control tumor growing and modulate antitumor immune responses.
3.1. Ectonucleotidases in a Model of Solid Tumor: Gliomas. Different signaling pathways, including the purinergic system, are involved in glioma progression [66].

It was previously showed that several glioma cells are resistant to cytotoxic ATP while this nucleotide promotes glioma proliferation [88, 89] and neuronal cell death [90]. We have shown that a variety of glioma cell lines (C6, U138MG, U251MG, and U87MG) exhibit diminished ATP hydrolysis (low ATPase/ADPase activities) and elevated capacity of hydrolyze AMP (high AMPase activity) when compared to astrocytes in culture [91]. According to enzymatic activity profile, glioma cells present low expression of NTPDase1/CD39, NTPDase2/CD39L1, and NTPDase3/CD39L3 in relation to astrocytes [66]. The same ectonucleotidases profile can be found in bladder tumor [67].

Notably, we also verified that the coinjection of apyrase (an ATP and ADP scavenger) with C6 glioma cells, in an in vivo glioma model, resulted in reduction of tumor growth, which was followed by a decreased inflammatory infiltrate, angiogenesis, and malignant characteristics [66]. NTPDase2/ CD39L1 overexpression in C6 glioma cells dramatically increased tumor growth, malignant characteristics, a sizable platelet sequestration and macrophage/microglial activation in the tumor area [92]. The NTPDase2/CD39L1, by preferentially removing ATP, may favor extracellular ADP accumulation and consequent $\mathrm{P} 2 \mathrm{Y}_{1}$ and $\mathrm{P} 2 \mathrm{Y}_{12}$ receptor modulation on glioma-associated platelets $[1,2]$. These data suggest that the ADP derived from NTPDase2/CD39L1 activity stimulates platelet migration to the tumor area and that NTPDase2/CD39L1, by regulating angiogenesis and inflammation, seems to play an important role in tumor progression [92]. In addition, to promote in vivo glioma growth, the NTPDase2/CD39L1 overexpression in tumor cells also modulated systemic inflammatory responses [93].

Likewise, previous studies have shown that C6 glioma cells exhibit NPP1 on the plasma membrane, which are responsible for the hydrolysis of low physiological extracellular ATP concentration $(1-10 \mu \mathrm{M})$ [94]. Interestingly Aerts et al. [95] have suggested that NPP1 can be a prognostic marker to glioma tumors since high grade tumors (grade II, III and IV) have increased NPP1 expression. Moreover, the ATP accumulation can be an explanation for the induction of NPP1 expression in glioma cells [95], which is in accordance with our hypothesis that ATP being degraded very slowly results in the accumulation of this nucleotide around the tumor $[66,95]$.

Many studies have demonstrated that the presence of inflammatory infiltrate is involved in tumor progression $[96,97]$. In gliomas, the presence of inflammatory infiltrate is directly correlated with tumor malignancy degree [98]. C6 glioma cells, in presence of ATP, release proinflammatory factors, such as MCP-1 and IL-8, important for the recruitment of monocytes and neutrophils, respectively [99]. When these immune cells reach the tumor environment, different stimuli modulate macrophage phenotype $[100,101]$. Several studies show that tumor-associated macrophages (TAMs) resemble an anti-inflammatory/M2 phenotype, in contrast to the proinflammatory/M1 phenotype [102, 103]. In agreement with these results, Komohara et al. [96] showed that patients 


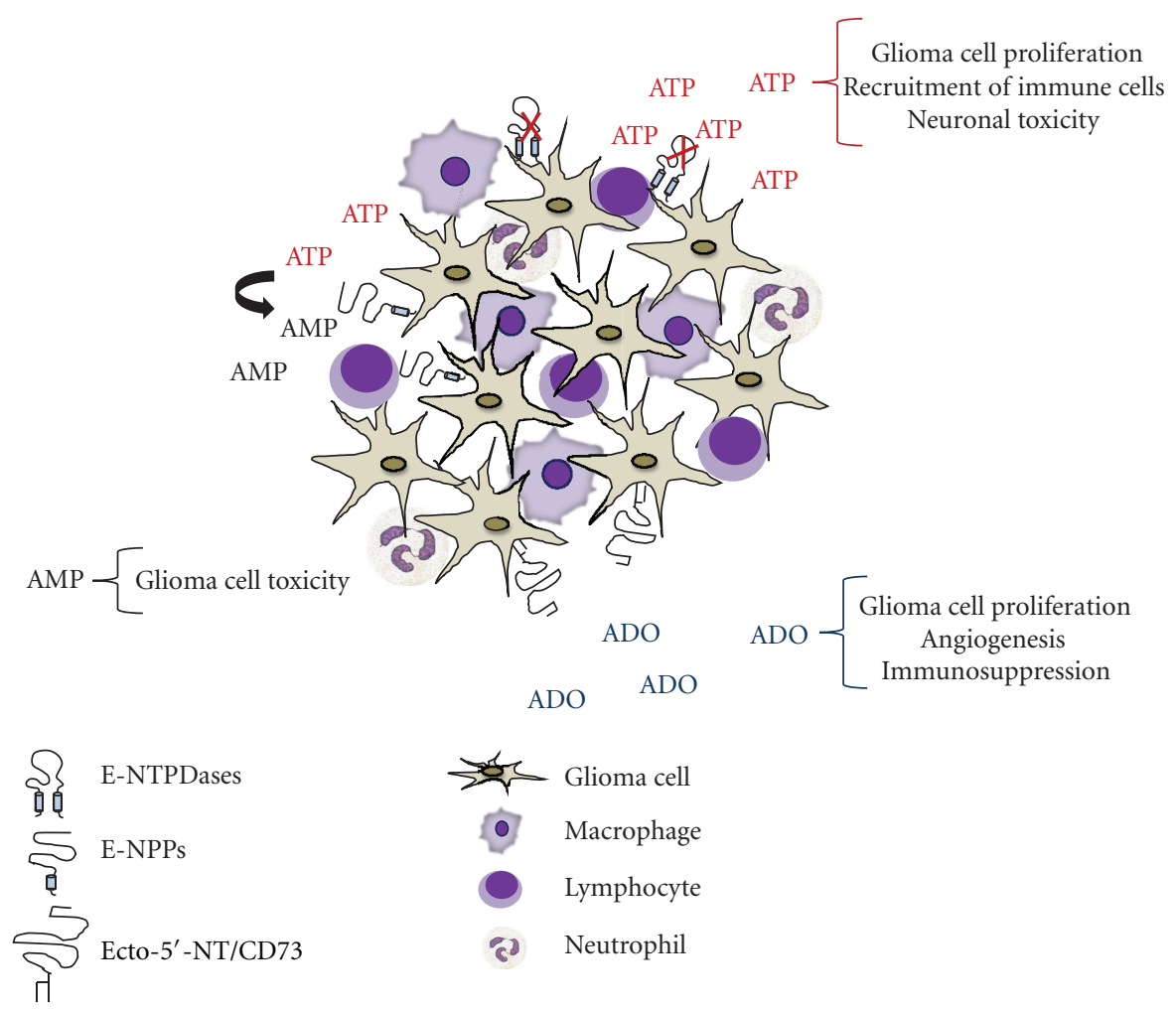

FIGURE 1: Ectonucleotidases in glioma progression. Glioma cells exhibit low ATP/ADP hydrolysis and a high AMP hydrolysis activity [91]. The inversion of extracellular nucleotide metabolism may favor extracellular ATP and adenosine accumulation within the tumor [51, 52, 66]. ATP could induce neuronal toxicity [90], glioma cell proliferation [88], and recruitment of immune cells by inducing the release of proinflammatory factors by tumor cells, such as MCP-1 and IL-8 [99]. Upon reaching the tumor, different stimuli modulate macrophage to M2 phenotype [100,101], and studies from our laboratory showed that ectonucleotidases are involved in the differentiation of macrophages [24]. The glioma cells exhibit NPP1 on the plasma membrane [94]; this enzyme generates AMP that is toxic for gliomas [74] but is the substrate for the ecto- $5^{\prime}-\mathrm{NT} / \mathrm{CD} 73$ which is highly expressed in glioma [74]. Ado, product of AMP hydrolysis could induce tumor cell proliferation, angiogenesis, and immunosuppression [56]. Therefore, the ATP and its hydrolytic products could be closely related to the immune responses involved in the glioma progression.

with glioblastoma multiforme have an increased infiltration of type M2 macrophages when compared to patients with lower-grade tumors. Therefore, by modulating multiple signaling pathways closely related to tumor malignancy, TAMs are considered key elements in the tumorigenesis processes. Studies are underway in our laboratory to establish if and how the ectonucleotidases would be involved in macrophage polarization in gliomas.

Hydrolysis of AMP by ecto- $5^{\prime}$-nucleotidase/CD73 action generates adenosine [1]. Glioblastoma multiforme is characterized by extensive hypoxia areas, which exhibit increased adenosine levels [52]. Adenosine has been recognized to mediate an immunosuppressive response to protect adjacent tissues of inflammation [57]. Furthermore, this nucleoside has been reported as mediator of cell proliferation and angiogenesis and also acts in tumor progression [56].

Previous results from our laboratory showed that increasing confluences led to an increase in ecto- $5^{\prime}-\mathrm{NT} /$ CD73 activity in glioma cell lines [74]. This event could be related to an increased ability to infiltrate the brain parenchyma, which constitutes the main cause of glioma recurrence
$[104,105]$. It was also shown that the inhibition of this ectoenzyme results in a decreased glioma cell proliferation. We suggested that this process is dependent on adenosine production parallel to AMP removal, a toxic molecule for gliomas [74]. Ohkubo et al. [106] have shown that adenosine inhibits cell proliferation of C6 glioma cells by its intracellular conversion to AMP. However, in our study, we showed that the stimulus of proliferation caused by adenosine is via extracellular effects instead of an adenosine uptake-dependent effect [74].

As in another solid cancer cited herein, the ecto- $5^{\prime}-\mathrm{NT} /$ CD73 is also involved in cell-cell and cell-matrix adhesion, key processes of tumor invasion and metastasis [107]. However, few studies are found in the literature relating the ecto-5'-NT/CD73 in invasion events of gliomas. Gessi et al. [108] showed that adenosine induced an increase of metalloproteinase-9, which is responsible for an increase of glioma cells invasion [108]. In a parallel investigation, we showed that exogenous adenosine promoted an increase in glioma cell adhesion in vitro, and the addition of selective inhibitor of this enzyme prevents this effect [109]. Therefore, 
this enzyme seems to play extreme importance in the glioma development. Taken together, these data indicate that suppression of ecto- $5^{\prime}-\mathrm{NT} / \mathrm{CD} 73$ activity at multiple levels, including tumor cells, may be a new tool to control tumor growing.

\section{Concluding Remarks}

Nucleotide/nucleoside receptor-mediated cell communication is orchestrated by ectonucleotidases, which efficiently hydrolyze ATP, ADP, and AMP to adenosine. The alterations in ectonucleotidases activity/expression may contribute to the physiopathological events observed in solid cancers as it has been studied in gliomas (Figure 1). In this paper, we summarized the main changes occurring in the expression/activity of ectonucleotidases in glioma cells as well in the tumor-associated immune cells. The development of therapeutic strategies targeting ectonucleotidases in tumor environment could offer promising finding.

\section{Abbreviations}

$\begin{array}{ll}\text { Ado: } & \text { Adenosine } \\ \text { ADP: } & \text { Adenosine diphosphate } \\ \text { ALP: } & \text { Ectoalkaline phosphatase } \\ \text { AMP: } & \text { Adenosine monophosphate } \\ \text { Apyrase: } & \text { Adenyl-pyrophosphatase } \\ \text { ATP: } & \text { Adenosine triphosphate } \\ \text { CDK: } & \text { Cyclindependent kinase } \\ \text { DC: } & \text { Dendritic cells } \\ \text { Ecto-5-NT/CD73: } & \text { Ecto-nucleotidase/CD73 } \\ \text { EGF: } & \text { Epidermal growth factor } \\ \text { EGFR: } & \text { Epidermal growth factor receptor } \\ \text { E-NPP: } & \text { Ectonucleotide } \\ & \text { pyrophosphatase/phosphodiesterase } \\ \text { E-NTPDase: } & \text { Ecto-nucleoside triphosphate } \\ \text { ERK: } & \text { diphosphohydrolase } \\ \text { FGF: } & \text { Extracellular signal-regulated kinases } \\ \text { INF- } \gamma: & \text { Fibroblast growth factor } \\ \text { IL-1 } \beta: & \text { Interferon-gamma } \\ \text { IL-2: } & \text { Interleukin1 beta } \\ \text { IL-6: } & \text { Interleukin 2 } \\ \text { IL-8: } & \text { Interleukin 6 } \\ \text { M1: } & \text { Interleukin 8 } \\ \text { M2: } & \text { Classical phenotype/proinflamma- } \\ \text { TAM: } & \text { tory } \\ \text { TNF- } \alpha: & \text { Alternative phenotype/antiinflam- } \\ \text { Tregs: } & \text { matory } \\ \text { NK: } & \text { Monocyte chemotactic protein-1 } \\ \text { PDGF: } & \text { Murine double minute 2 } \\ \text { RB1: } & \text { Patural killer cells } \\ & \text { Platelet-derived growth factor } \\ \text { Thetinoblastoma } & \end{array}$

\section{Acknowledgments}

The authors would like to thank Dr. Marcia R. Wink, Departamento de Ciências Básicas da Saúde, UFCSPA, Porto Alegre, RS, Brasil, Dr. Fernanda B. Morrone, Faculdade de Farmácia, PUCRS, Porto Alegre, RS, Brasil, Dr. Guido Lenz, Departamento de Biofísica, IB e Centro de Biotecnologia, UFRGS, Porto Alegre, RS, Brasil, Dr. Marco Antonio Stefani, Serviço de Neurologia, HCPA, UFRGS, Porto Alegre, RS, Brasil; Dr. Simon C. Robson, Beth Israel Deaconess Medical Center, Harvard University, Boston, MA, USA, and Dr. Jean Sevigny, Centre de Recherche en Rheumatologie et Immunologie, Centre Hospitalier Universitaire de Québec (Pavillon CHUL) and Département de Microbiologie-Infectiologie et d'Immunologie, Faculté de Médecine, Université Laval, Québec, QC, Canada, for their collaboration in the glioma studies. The authors also acknowledge the Brazilian Funding Agencies: CNPq, CAPES, FIPE-HCPA (Projeto 11-0101) and FAPERGS (Processo 10/0286-2) for the financial support.

\section{References}

[1] H. Zimmermann, M. Zebisch, and N. Sträter, "Cellular function and molecular structure of ecto-nucleotidases," Purinergic Signalling, vol. 8, no. 3, pp. 437-502, 2012.

[2] S. C. Robson, J. Sévigny, and H. Zimmermann, "The ENTPDase family of ectonucleotidases: structure function relationships and pathophysiological significance," Purinergic Signalling, vol. 2, no. 2, pp. 409-430, 2006.

[3] L. Plesner, "Ecto-ATPases: identities and functions," International Review of Cytology, vol. 158, pp. 141-214, 1995.

[4] F. Bigonnesse, S. A. Lévesque, F. Kukulski et al., "Cloning and characterization of mouse nucleoside triphosphate diphosphohydrolase-8," Biochemistry, vol. 43, no. 18, pp. 55115519, 2004.

[5] B. P. Chadwick and A. M. Frischauf, "The CD39-like gene family: identification of three new human members (CD39L2, CD39L3, and CD39L4), their murine homologues, and a member of the gene family from Drosophila melanogaster," Genomics, vol. 50, no. 3, pp. 357-367, 1998.

[6] P. Heine, N. Braun, A. Heilbronn, and H. Zimmermann, "Functional characterization of rat ecto-ATPase and ectoATP diphosphohydrolase after heterologous expression in CHO cells," European Journal of Biochemistry, vol. 262, no. 1, pp. 102-107, 1999.

[7] E. Kaczmarek, K. Koziak, J. Sévigny et al., "Identification and characterization of CD39/vascular ATP diphosphohydrolase," The Journal of Biological Chemistry, vol. 271, no. 51, pp. 33116-33122, 1996.

[8] B. Kegel, N. Braun, P. Heine, C. R. Maliszewski, and H. Zimmermann, "An ecto-ATPase and an ecto-ATP diphosphohydrolase are expressed in rat brain," Neuropharmacology, vol. 36, no. 9, pp. 1189-1200, 1997.

[9] T. M. Smith and T. L. Kirley, "Cloning, sequencing, and expression of a human brain ecto-apyrase related to both the ecto-ATPases and CD39 ecto-apyrases," Biochimica et Biophysica Acta, vol. 1386, no. 1, pp. 65-78, 1998.

[10] H. Zimmermann, "Extracellular metabolism of ATP and other nucleotides," Naunyn-Schmiedeberg's Archives of Pharmacology, vol. 362, no. 4-5, pp. 299-309, 2000.

[11] M. Bollen, R. Gijsbers, H. Ceulemans, W. Stalmans, and C. Stefan, "Nucleotide pyrophosphatases/phosphodiesterases 
on the move," Critical Reviews in Biochemistry and Molecular Biology, vol. 35, no. 6, pp. 393-432, 2000.

[12] J. W. Goding, B. Grobben, and H. Slegers, "Physiological and pathophysiological functions of the ecto-nucleotide pyrophosphatase/phosphodiesterase family," Biochimica et Biophysica Acta, vol. 1638, no. 1, pp. 1-19, 2003.

[13] H. Zimmermann, " 5 '-Nucleotidase: molecular structure and functional aspects," Biochemical Journal, vol. 285, no. 2, pp. 345-365, 1992.

[14] R. Sadej, J. Spychala, and A. C. Skladanowski, "Expression of ecto-5' -nucleotidase ( $\mathrm{eN}, \mathrm{CD} 73)$ in cell lines from various stages of human melanoma," Melanoma Research, vol. 16, no. 3, pp. 213-222, 2006.

[15] R. Sadej, K. Inai, Z. Rajfur et al., "Tenascin C interacts with Ecto-5' -nucleotidase $(\mathrm{eN})$ and regulates adenosine generation in cancer cells," Biochimica et Biophysica Acta, vol. 1782, no. 1, pp. 35-40, 2008.

[16] P. Zhou, X. Zhi, T. Zhou et al., "Overexpression of ecto-5'nucleotidase (CD73) promotes T-47D human breast cancer cells invasion and adhesion to extracellular matrix," Cancer Biology and Therapy, vol. 6, no. 3, pp. 426-431, 2007.

[17] M. J. L. Bours, E. L. R. Swennen, F. Di Virgilio, B. N. Cronstein, and P. C. Dagnelie, "Adenosine 5'-triphosphate and adenosine as endogenous signaling molecules in immunity and inflammation," Pharmacology and Therapeutics, vol. 112, no. 2, pp. 358-404, 2006.

[18] R. Coutinho-Silva, J. L. Perfettini, P. M. Persechini, A. Dautry-Varsat, and D. M. Ojcius, "Modulation of P2Z/P2X7 receptor activity in macrophages infected with Chlamydia psittaci," American Journal of Physiology, vol. 280, no. 1, pp. C81-C89, 2001.

[19] D. Perregaux and C. A. Gabel, "Interleukin-1 $\beta$ maturation and release in response to ATP and nigericin. Evidence that potassium depletion mediated by these agents is a necessary and common feature of their activity," The Journal of Biological Chemistry, vol. 269, no. 21, pp. 15195-15203, 1994.

[20] S. Deaglio and S. C. Robson, "Ectonucleotidases as regulators of purinergic signaling in thrombosis, inflammation and immunity," Advances in Pharmacology, vol. 61, pp. 301-332, 2011.

[21] C. R. Maliszewski, G. J. T. Delespesse, M. A. Schoenborn et al., "The CD39 lymphoid cell activation antigen: molecular cloning and structural characterization," The Journal of Immunology, vol. 153, no. 8, pp. 3574-3583, 1994.

[22] K. Koziak, J. Sévigny, S. C. Robson, J. B. Siegel, and E. Kaczmarek, "Analysis of CD39/ATP diphosphohydrolase (ATPDase) expression in endothelial cells, platelets and leukocytes," Thrombosis and Haemostasis, vol. 82, no. 5, pp. 1538-1544, 1999.

[23] V. Kumar and A. Sharma, "Adenosine: an endogenous modulator of innate immune system with therapeutic potential," European Journal of Pharmacology, vol. 616, no. 1-3, pp. 7$15,2009$.

[24] R. F. Zanin, E. Braganhol, L. S. Bergamin et al., "Differential macrophage activation alters the expression profile of NTPDase and Ecto-5' -nucleotidase," PLOS ONE, vol. 7, no. 2, Article ID e31205, 2012.

[25] F. Kukulski, F. Bahrami, F. Ben Yebdri et al., "NTPDase1 controls IL-8 production by human neutrophils," The Journal of Immunology, vol. 187, no. 2, pp. 644-653, 2011.

[26] S. A. Lévesque, F. Kukulski, K. Enjyoji, S. C. Robson, and J. Sévigny, "NTPDase1 governs P2X7-dependent functions in murine macrophages," European Journal of Immunology, vol. 40, no. 5, pp. 1473-1485, 2010.
[27] K. E. Dombrowski, J. M. Trevillyan, J. C. Cone, Y. Lu, and C. A. Phillips, "Identification and partial characterization of an EctoATPase expressed by human natural killer cells," Biochemistry, vol. 32, no. 26, pp. 6515-6522, 1993.

[28] K. E. Dombrowski, Y. Ke, L. F. Thompson, and J. A. Kapp, "Antigen recognition by CTL is dependent upon ectoATPase activity," The Journal of Immunology, vol. 154, no. 12, pp. 6227-6237, 1995.

[29] K. E. Dombrowski, J. C. Cone, J. M. Bjorndahl, and C. A. Phillips, "Irreversible inhibition of human natural killer cell natural cytotoxicity by modification of the extracellular membrane by the adenine nucleotide analog 5'-p-(fluorosulfonyl)benzoyl adenosine," Cellular Immunology, vol. 160, no. 2, pp. 199-204, 1995.

[30] H. P. Langston, Y. Ke, A. T. Gewirtz, K. E. Dombrowski, and J. A. Kapp, "Secretion of IL-2 and IFN- $\gamma$, but not IL-4, by antigen-specific T cells requires extracellular ATP," The Journal of Immunology, vol. 170, no. 6, pp. 2962-2970, 2003.

[31] H. Tsukamoto, P. Chernogorova, K. Ayata et al., "Deficiency of CD73/ecto-5' -nucleotidase in mice enhances acute graftversus-host disease," Blood, vol. 119, no. 19, pp. 4554-4564, 2012.

[32] M. Mandapathil, M. J. Szczepanski, M. Szajnik et al., "Increased ectonucleotidase expression and activity in regulatory T cells of patients with head and neck cancer," Clinical Cancer Research, vol. 15, no. 20, pp. 6348-6357, 2009.

[33] G. Borsellino, M. Kleinewietfeld, D. Di Mitri et al., "Expression of ectonucleotidase CD39 by Foxp $3^{+}$Treg cells: hydrolysis of extracellular ATP and immune suppression," Blood, vol. 110, no. 4, pp. 1225-1232, 2007.

[34] S. Deaglio, K. M. Dwyer, W. Gao et al., "Adenosine generation catalyzed by CD39 and CD73 expressed on regulatory T cells mediates immune suppression," Journal of Experimental Medicine, vol. 204, no. 6, pp. 1257-1265, 2007.

[35] M. Miyara and S. Sakaguchi, "Natural regulatory T cells: mechanisms of suppression," Trends in Molecular Medicine, vol. 13, no. 3, pp. 108-116, 2007.

[36] T. L. Whiteside, M. Mandapathil, and P. Schuler, "The role of the adenosinergic pathway in immunosuppression mediated by human regulatory T cells (Treg)," Current Medicinal Chemistry, vol. 18, no. 34, pp. 5217-5223, 2011.

[37] A. V. Sauer, I. Brigida, N. Carriglio et al., "Alterations in the adenosine metabolism and CD39/CD73 adenosinergic machinery cause loss of Treg cell function and autoimmunity in ADA-deficient SCID," Blood, vol. 119, no. 6, pp. 1428$1439,2012$.

[38] Y. Tang, L. Jiang, Y. Zheng, B. Ni, and Y. Wu, "Expression of $\mathrm{CD} 39$ on FoxP3 ${ }^{+} \mathrm{T}$ regulatory cells correlates with progression of HBV infection," BMC Immunology, vol. 13, article $17,2012$.

[39] M. J. Loza, A. Shane Anderson, K. S. O'Rourke, J. Wood, and I. U. Khan, "T-cell specific defect in expression of the NTPDase CD39 as a biomarker for lupus," Cellular Immunology, vol. 271, no. 1, pp. 110-117, 2011.

[40] M. C. Hyman, D. Petrovic-Djergovic, S. H. Visovatti et al., "Self-regulation of inflammatory cell trafficking in mice by the leukocyte surface apyrase CD39," The Journal of Clinical Investigation, vol. 119, no. 5, pp. 1136-1149, 2009.

[41] P. Pelegrin and A. Surprenant, "Dynamics of macrophage polarization reveal new mechanism to inhibit IL-1beta release through pyrophosphates," The EMBO Journal, vol. 28, no. 14, pp. 2114-2127, 2009.

[42] A. La Sala, D. Ferrari, S. Corinti, A. Cavani, F. Di Virgilio, and G. Girolomoni, "Extracellular ATP induces a distorted 
maturation of dendritic cells and inhibits their capacity to initiate Th1 responses," The Journal of Immunology, vol. 166, no. 3, pp. 1611-1617, 2001.

[43] N. Mizumoto, T. Kumamoto, S. C. Robson et al., "CD39 is the dominant Langerhans cell-associated ecto-NTPDase: modulatory roles in inflammation and immune responsiveness," Nature Medicine, vol. 8, no. 4, pp. 358-365, 2002.

[44] R. Corriden, Y. Chen, Y. Inoue et al., "Ecto-nucleoside triphosphate diphosphohydrolase 1 (E-NTPDase1/CD39) regulates neutrophil chemotaxis by hydrolyzing released ATP to adenosine," The Journal of Biological Chemistry, vol. 283, no. 42, pp. 28480-28486, 2008.

[45] D. N. Louis, "The p53 gene and protein in human brain tumors," Journal of Neuropathology and Experimental Neurology, vol. 53, no. 1, pp. 11-21, 1994.

[46] A. von Deimling, D. N. Louis, and O. D. Wiestler, "Molecular pathways in the formation of gliomas," Glia, vol. 15, no. 3, pp. 328-338, 1995.

[47] E. A. Maher, F. B. Furnari, R. M. Bachoo et al., "Malignant glioma: genetics and biology of a grave matter," Genes and Development, vol. 15, no. 11, pp. 1311-1333, 2001.

[48] J. R. Shapiro, "Genetics of brain neoplasms," Current Neurology and Neuroscience Reports, vol. 1, no. 3, pp. 217-224, 2001.

[49] A. Mantovani, "Cancer: inflaming metastasis," Nature, vol. 457, no. 7225, pp. 36-37, 2009.

[50] T. Takano, J. H. C. Lin, G. Arcuino, Q. Gao, J. Yang, and M. Nedergaard, "Glutamate release promotes growth of malignant gliomas," Nature Medicine, vol. 7, no. 9, pp. 1010-1015, 2001.

[51] P. Pellegatti, L. Raffaghello, G. Bianchi, F. Piccardi, V. Pistoia, and F. Di Virgilio, "Increased level of extracellular ATP at tumor sites: in vivo imaging with plasma membrane luciferase," PLoS ONE, vol. 3, no. 7, Article ID e2599, 2008.

[52] A. Melani, E. De Micheli, G. Pinna, A. Alfieri, L. D. Corte, and F. Pedata, "Adenosine extracellular levels in human brain gliomas: an intraoperative microdialysis study," Neuroscience Letters, vol. 346, no. 1-2, pp. 93-96, 2003.

[53] J. K. Ryu, H. B. Choi, K. Hatori et al., "Adenosine triphosphate induces proliferation of human neural stem cells: role of calcium and p70 ribosomal protein S6 kinase," Journal of Neuroscience Research, vol. 72, no. 3, pp. 352-362, 2003.

[54] G. Lenz, C. Gottfried, L. Zhijun et al., "P(2Y) purinoceptor subtypes recruit different Mek activators in astrocytes," British Journal of Pharmacology, vol. 129, no. 5, pp. 927-936, 2000.

[55] J. T. Neary, Y. Kang, K. A. Willoughby, and E. F. Ellis, "Activation of extracellular signal-regulated kinase by stretchinduced injury in astrocytes involves extracellular ATP and P2 purinergic receptors," Journal of Neuroscience, vol. 23, no. 6, pp. 2348-2356, 2003.

[56] J. Spychala, "Tumor-promoting functions of adenosine," Pharmacology and Therapeutics, vol. 87, no. 2-3, pp. 161-173, 2000.

[57] A. Ohta, E. Gorelik, S. J. Prasad et al., " $\mathrm{A}_{2 \mathrm{~A}}$ adenosine receptor protects tumors from antitumor T cells," Proceedings of the National Academy of Sciences of the United States of America, vol. 103, no. 35, pp. 13132-13137, 2006.

[58] E. R. Lazarowski, R. C. Boucher, and T. K. Harden, "Constitutive release of ATP and evidence for major contribution of ecto-nucleotide pyrophosphatase and nucleoside diphosphokinase to extracellular nucleotide concentrations," The Journal of Biological Chemistry, vol. 275, no. 40, pp. 3106131068, 2000.
[59] M. P. Abbracchio, G. Burnstock, J. M. Boeynaems et al., "International Union of Pharmacology LVIII: update on the P2Y G protein-coupled nucleotide receptors: from molecular mechanisms and pathophysiology to therapy," Pharmacological Reviews, vol. 58, no. 3, pp. 281-341, 2006.

[60] S. F. Okada, R. A. Nicholas, S. M. Kreda, E. R. Lazarowski, and R. C. Boucher, "Physiological regulation of ATP release at the apical surface of human airway epithelia," The Journal of Biological Chemistry, vol. 281, no. 32, pp. 22992-23002, 2006.

[61] G. Burnstock, "Purinergic signalling: its unpopular beginning, its acceptance and its exciting future," BioEssays, vol. 34, no. 3, pp. 218-225, 2012.

[62] S. F. M. Häusler, I. Montalbán del Barrio, J. Strohschein et al., "Ectonucleotidases CD39 and CD73 on OvCA cells are potent adenosine-generating enzymes responsible for adenosine receptor 2A-dependent suppression of $\mathrm{T}$ cell function and NK cell cytotoxicity," Cancer Immunology, Immunother$a p y$, vol. 60, no. 10, pp. 1405-1418, 2011.

[63] A. Buffon, M. R. Wink, B. V. Ribeiro et al., "NTPDase and $5^{\prime}$ ecto-nucleotidase expression profiles and the pattern of extracellular ATP metabolism in the Walker 256 tumor," Biochimica et Biophysica Acta, vol. 1770, no. 8, pp. 1259-1265, 2007.

[64] K. N. Dzhandzhugazyan, A. F. Kirkin, P. Thor Straten, and J. Zeuthen, "Ecto-ATP diphosphohydrolase/CD39 is overexpressed in differentiated human melanomas," FEBS Letters, vol. 430, no. 3, pp. 227-230, 1998.

[65] B. M. Künzli, M. I. Bernlochner, S. Rath et al., "Impact of CD39 and purinergic signalling on the growth and metastasis of colorectal cancer," Purinergic Signalling, vol. 7, no. 2, pp. 231-241, 2011.

[66] F. B. Morrone, D. L. Oliveira, P. Gamermann et al., "In vivo glioblastoma growth is reduced by apyrase activity in a rat glioma model," BMC Cancer, vol. 6, article 226, 2006.

[67] J. Stella, L. Bavaresco, E. Braganhol et al., "Differential ectonucleotidase expression in human bladder cancer cell lines," Urologic Oncology, vol. 28, no. 3, pp. 260-267, 2010.

[68] S. W. Jackson, T. Hoshi, Y. Wu et al., "Disordered purinergic signaling inhibits pathological angiogenesis in Cd39/Entpd1null mice," American Journal of Pathology, vol. 171, no. 4, pp. 1395-1404, 2007.

[69] X. Sun, Y. Wu, W. Gao et al., "CD39/ENTPD1 expression by $\mathrm{CD}^{+} \mathrm{Foxp}^{+}$regulatory $\mathrm{T}$ cells promotes hepatic metastatic tumor growth in mice," Gastroenterology, vol. 139, no. 3, pp. 1030-1040, 2010.

[70] L. Feng, X. Sun, E. Csizmadia et al., "Vascular CD39/ ENTPD1 directly promotes tumor cell growth by scavenging extracellular adenosine triphosphate," Neoplasia, vol. 13, no. 3, pp. 206-216, 2011.

[71] S. P. Hilchey, J. J. Kobie, M. R. Cochran et al., "Human follicular lymphoma CD39+-infiltrating $\mathrm{T}$ cells contribute to adenosine-mediated T cell hyporesponsiveness," The Journal of Immunology, vol. 183, no. 10, pp. 6157-6166, 2009.

[72] D. Jin, J. Fan, L. Wang et al., "CD73 on tumor cells impairs antitumor T-cell responses: a novel mechanism of tumorinduced immune suppression," Cancer Research, vol. 70, no. 6, pp. 2245-2255, 2010.

[73] L. Wang, J. Fan, L. F. Thompson et al., "CD73 has distinct roles in nonhematopoietic and hematopoietic cells to promote tumor growth in mice," The Journal of Clinical Investigation, vol. 121, no. 6, pp. 2371-2382, 2011.

[74] L. Bavaresco, A. Bernardi, E. Braganhol et al., "The role of ecto-5' ${ }^{\prime}$-nucleotidase/CD73 in glioma cell line proliferation," 
Molecular and Cellular Biochemistry, vol. 319, no. 1-2, pp. 6168, 2008.

[75] R. Sadej, J. Spychala, and A. C. Skladanowski, "Expression of ecto-55'-nucleotidase (eN, CD73) in cell lines from various stages of human melanoma," Melanoma Research, vol. 16, no. 3, pp. 213-222, 2006.

[76] S. Y. Cho, J. Polster, J. M. Engles, J. Hilton, E. H. Abraham, and R. L. Wahl, "In vitro evaluation of adenosine 5 '-monophosphate as an imaging agent of tumor metabolism," Journal of Nuclear Medicine, vol. 47, no. 5, pp. 837-845, 2006.

[77] T. Kondo, T. Nakazawa, S. I. Murata, and R. Katoh, "Expression of CD73 and its ecto- $5^{\prime}$-nucleotidase activity are elevated in papillary thyroid carcinomas," Histopathology, vol. 48, no. 5, pp. 612-614, 2006.

[78] K. Fukuda, C. Sakakura, K. Miyagawa et al., "Differential gene expression profiles of radio resistant oesophageal cancer cell lines established by continuous fractionated irradiation," British Journal of Cancer, vol. 91, no. 8, pp. 1543-1550, 2004.

[79] C. Hastie, M. Saxton, A. Akpan, R. Cramer, J. R. Masters, and S. Naaby-Hansen, "Combined affinity labelling and mass spectrometry analysis of differential cell surface protein expression in normal and prostate cancer cells," Oncogene, vol. 24, no. 38, pp. 5905-5913, 2005.

[80] J. Spychala, E. Lazarowski, A. Ostapkowicz, L. H. Ayscue, A. Jin, and B. S. Mitchell, "Role of estrogen receptor in the regulation of ecto- $5^{\prime}$-nucleotidase and adenosine in breast cancer," Clinical Cancer Research, vol. 10, no. 2, pp. 708-717, 2004.

[81] L. Wang, X. Zhou, T. Zhou et al., "Ecto-5'-nucleotidase promotes invasion, migration and adhesion of human breast cancer cells," Journal of Cancer Research and Clinical Oncology, vol. 134, no. 3, pp. 365-372, 2008.

[82] V. Singh Ghalaut, K. Dahiya, P. S. Ghalaut, S. Batra, and R. Dhankhar, "Lymphocytic ecto $5^{\prime}$-nucleotidase (ecto-5'NT) levels in acute lymphoblastic leukemia and non-Hodgkin's lymphoma," Clinica Chimica Acta, vol. 364, no. 1-2, pp. 359360, 2006.

[83] J. Stagg, U. Divisekera, N. McLaughlin et al., "Anti-CD73 antibody therapy inhibits breast tumor growth and metastasis," Proceedings of the National Academy of Sciences of the United States of America, vol. 107, no. 4, pp. 1547-1552, 2010.

[84] X. Zhi, S. Chen, P. Zhou et al., "RNA interference of ecto5 '-nucleotidase (CD73) inhibits human breast cancer cell growth and invasion," Clinical and Experimental Metastasis, vol. 24, no. 6, pp. 439-448, 2007.

[85] G. G. Yegutkin, F. Marttila-Ichihara, M. Karikoski et al., "Altered purinergic signaling in CD73-deficient mice inhibits tumor progression," European Journal of Immunology, vol. 41, no. 5, pp. 1231-1241, 2011.

[86] J. Stagg, U. Divisekera, H. Duret et al., "CD73-deficient mice have increased antitumor immunity and are resistant to experimental metastasis," Cancer Research, vol. 71, no. 8, pp. 2892-2900, 2011.

[87] J. Stagg, P. A. Beavis, U. Divisekera et al., "CD73-Deficient mice are resistant to carcinogenesis," Cancer Research, vol. 72, no. 9, pp. 2190-2196, 2012.

[88] F. B. Morrone, M. C. Jacques-Silva, A. P. Horn et al., "Extracellular nucleotides and nucleosides induce proliferation and increase nucleoside transport in human glioma cell lines," Journal of Neuro-Oncology, vol. 64, no. 3, pp. 211-218, 2003.

[89] F. B. Morrone, A. P. Horn, J. Stella et al., "Increased resistance of glioma cell lines to extracellular ATP cytotoxicity," Journal of Neuro-Oncology, vol. 71, no. 2, pp. 135-140, 2005.
[90] S. Amadio, N. D’Ambrosi, F. Cavaliere et al., "P2 receptor modulation and cytotoxic function in cultured CNS neurons," Neuropharmacology, vol. 42, no. 4, pp. 489-501, 2002.

[91] M. R. Wink, G. Lenz, E. Braganhol et al., "Altered extracellular ATP, ADP and AMP catabolism in glioma cell lines," Cancer Letters, vol. 198, no. 2, pp. 211-218, 2003.

[92] E. Braganhol, F. B. Morrone, A. Bernardi et al., "Selective NTPDase2 expression modulates in vivo rat glioma growth," Cancer Science, vol. 100, no. 8, pp. 1434-1442, 2009.

[93] E. Braganhol, R. F. Zanin, A. Bernardi et al., "Overexpression of NTPDase2 in gliomas promotes systemic inflammation and pulmonary injury," Purinergic Signalling, vol. 8, no. 2, pp. 235-243, 2012.

[94] B. Grobben, K. Anciaux, D. Roymans et al., "An ecto-nucleotide pyrophosphatase is one of the main enzymes involved in the extracellular metabolism of ATP in rat C6 glioma," Journal of Neurochemistry, vol. 72, no. 2, pp. 826-834, 1999.

[95] I. Aerts, J. J. Martin, P. P. D. Deyn et al., "The expression of ecto-nucleotide pyrophosphatase/phosphodiesterase 1 (ENPP1) is correlated with astrocytic tumor grade," Clinical Neurology and Neurosurgery, vol. 113, no. 3, pp. 224-229, 2011.

[96] Y. Komohara, K. Ohnishi, J. Kuratsu, and M. Takeya, "Possible involvement of the M2 anti-inflammatory macrophage phenotype in growth of human gliomas," Journal of Pathology, vol. 216, no. 1, pp. 15-24, 2008.

[97] R. Mora, A. Abschuetz, T. Kees et al., "TNF- $\alpha$ - and TRAILresistant glioma cells undergo autophagy-dependent cell death induced by activated microglia," Glia, vol. 57, no. 5, pp. 561-581, 2009.

[98] J. J. Watters, J. M. Schartner, and B. Badie, "Microglia function in brain tumors," Journal of Neuroscience Research, vol. 81, no. 3, pp. 447-455, 2005.

[99] N. Jantaratnotai, H. B. Choi, and J. G. McLarnon, "ATP stimulates chemokine production via a store-operated calcium entry pathway in C6 glioma cells," BMC Cancer, vol. 9, article 442, 2009.

[100] A. Sica and V. Bronte, "Altered macrophage differentiation and immune dysfunction in tumor development," The Journal of Clinical Investigation, vol. 117, no. 5, pp. 1155-1166, 2007.

[101] G. Solinas, G. Germano, A. Mantovani, and P. Allavena, "Tumor-associated macrophages (TAM) as major players of the cancer-related inflammation," Journal of Leukocyte Biology, vol. 86, no. 5, pp. 1065-1073, 2009.

[102] F. Balkwill and A. Mantovani, "Inflammation and cancer: back to Virchow?" The Lancet, vol. 357, no. 9255, pp. 539545, 2001.

[103] L. M. Coussens and Z. Werb, "Inflammation and cancer," Nature, vol. 420, no. 6917, pp. 860-867, 2002.

[104] N. Sanai, A. Alvarez-Buylla, and M. S. Berger, "Mechanisms of disease: neural stem cells and the origin of gliomas," The New England Journal of Medicine, vol. 353, no. 8, pp. 811-822, 2005.

[105] S. K. Singh, I. D. Clarke, T. Hide, and P. B. Dirks, "Cancer stem cells in nervous system tumors," Oncogene, vol. 23, no. 43, pp. 7267-7273, 2004.

[106] S. Ohkubo, K. Nagata, and N. Nakahata, "Adenosine uptakedependent C6 cell growth inhibition," European Journal of Pharmacology, vol. 577, no. 1-3, pp. 35-43, 2007.

[107] B. Zhang, "CD73 promotes tumor growth and metastasis," Oncoimmunology, vol. 1, no. 1, pp. 67-70, 2012.

[108] S. Gessi, V. Sacchetto, E. Fogli et al., "Modulation of metalloproteinase-9 in U87MG glioblastoma cells by A3 adenosine 
receptors," Biochemical Pharmacology, vol. 79, no. 10, pp. 1483-1495, 2010.

[109] A. R. Cappellari, G. J. Vasques, L. Bavaresco, E. Braganhol, and A. M. O. Battastini, "Involvement of ecto-5'-nucleotidase/CD73 in U138MG glioma cell adhesion," Molecular and Cellular Biochemistry, vol. 359, no. 1-2, pp. 315-322, 2012. 

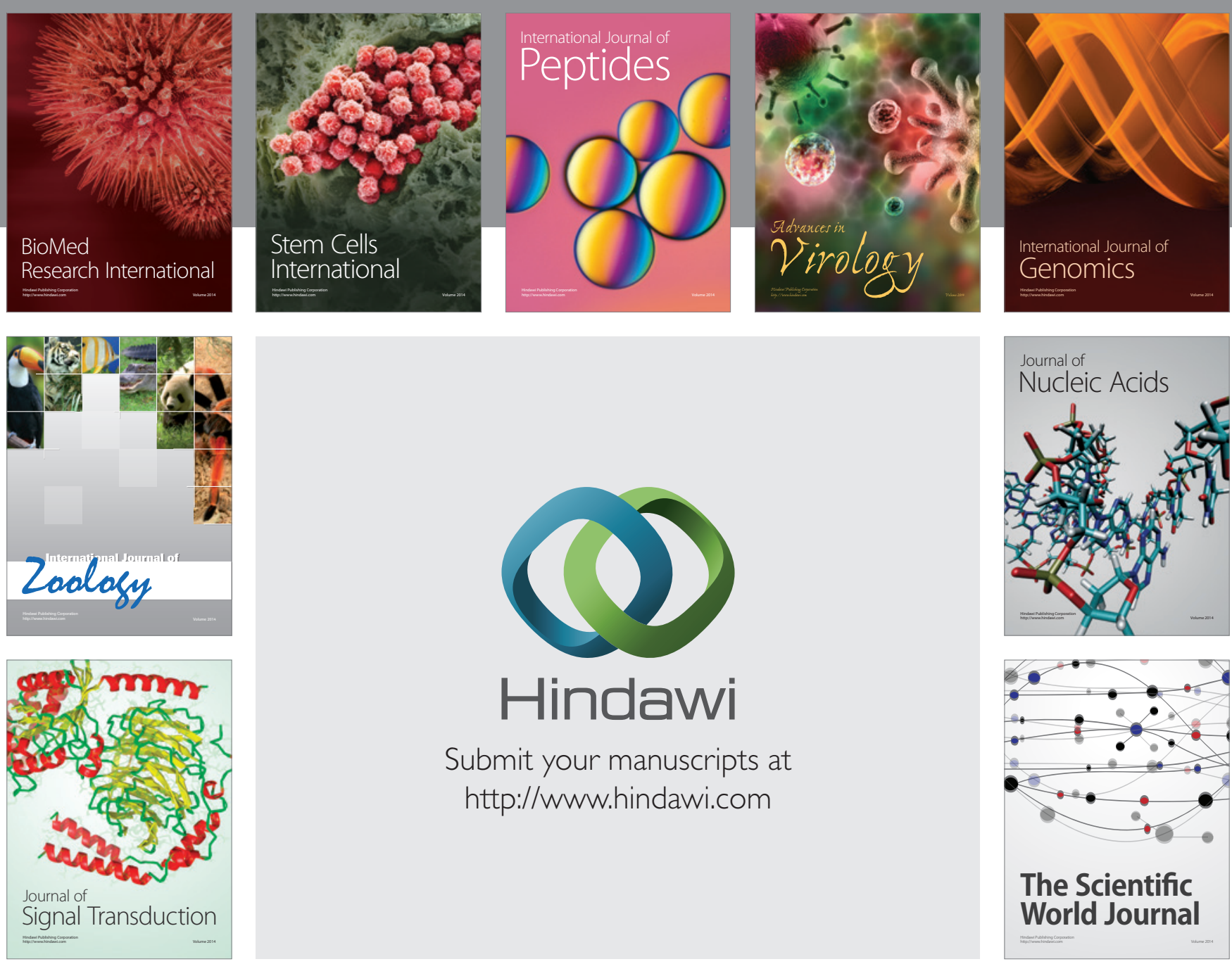

Submit your manuscripts at

http://www.hindawi.com
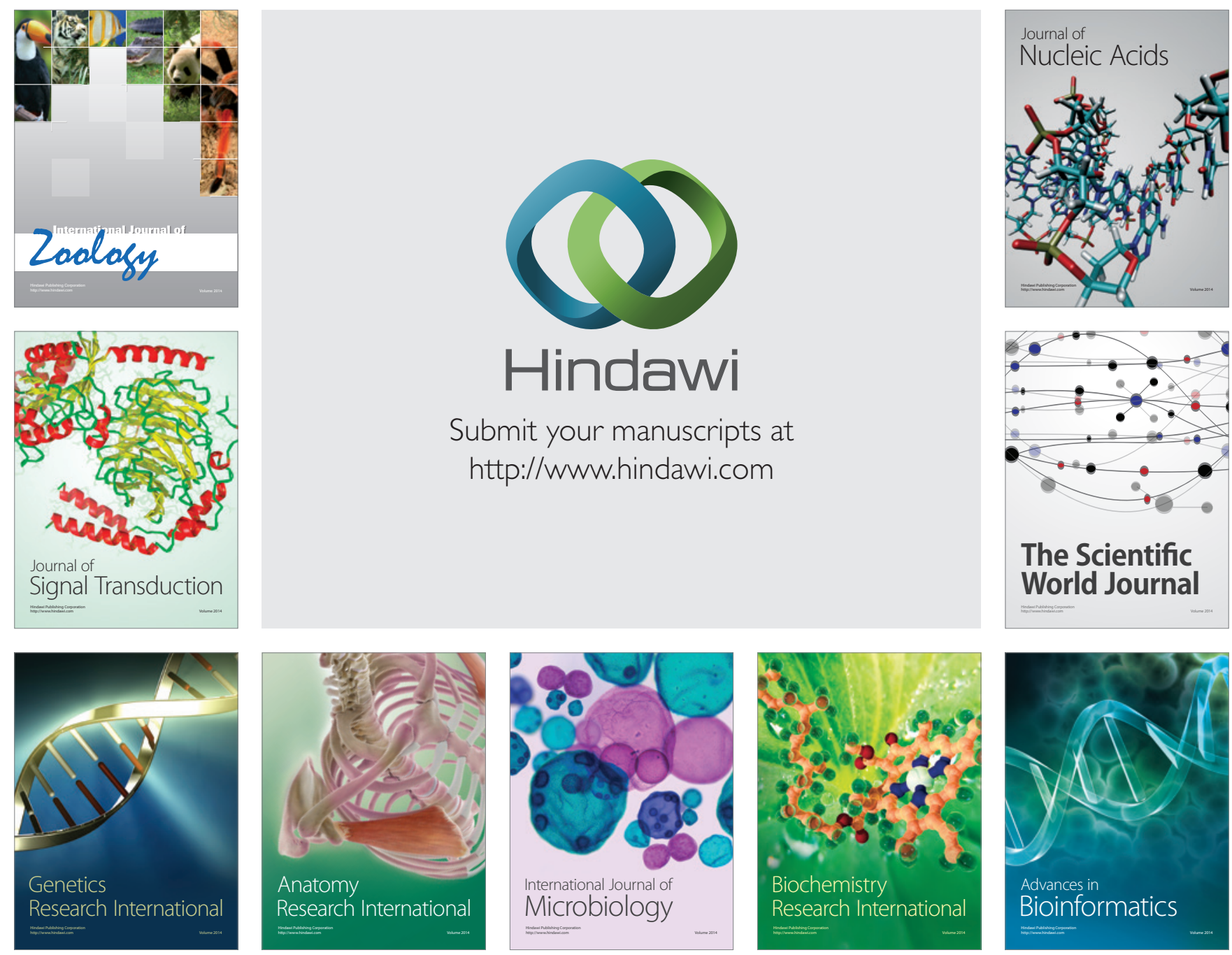

The Scientific World Journal
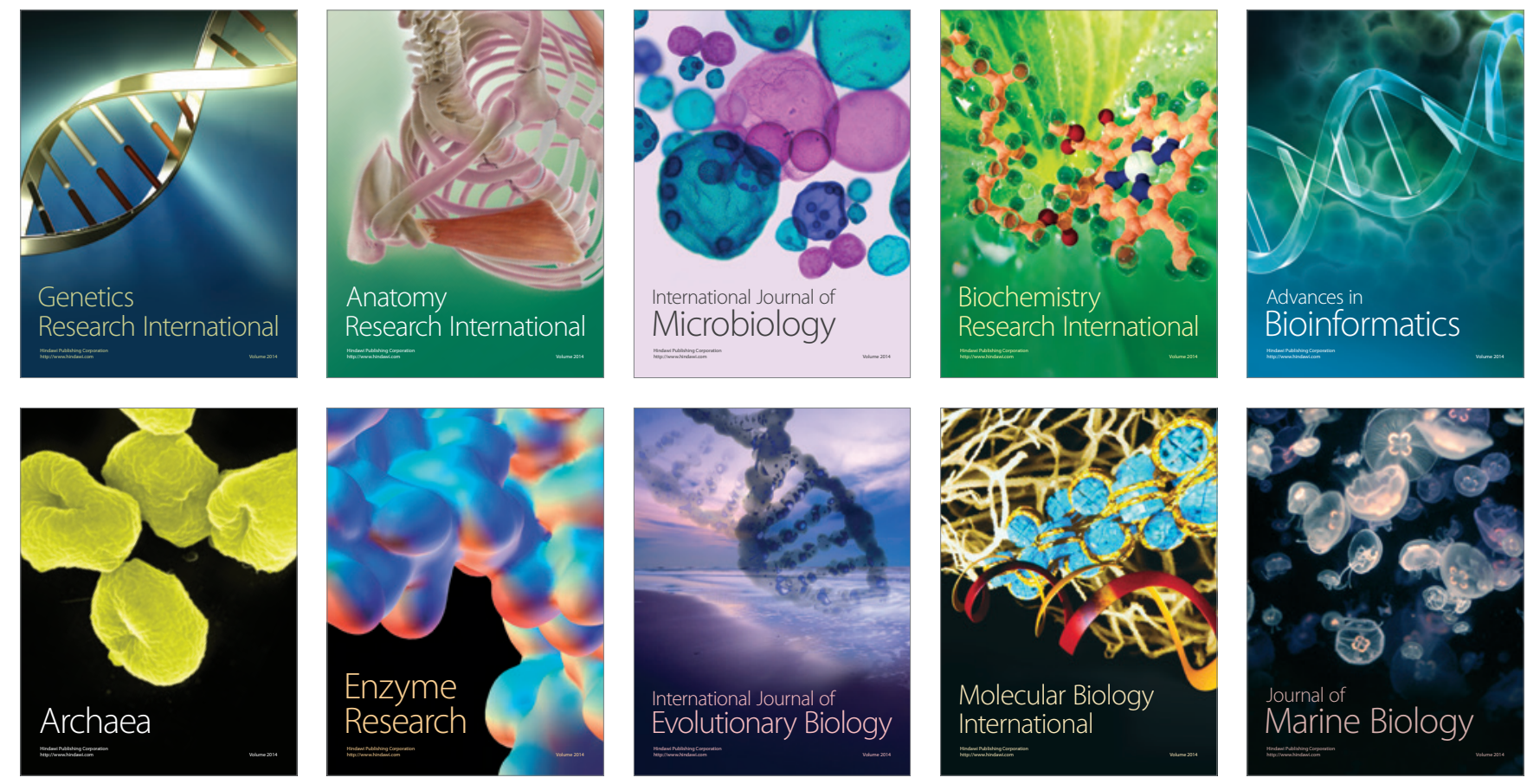